\title{
STUDY OF ACCIDENTAL DEATH DUE TO ROAD TRAFFIC ACCIDENTAL CASES RECORDED AT FORENSIC MEDICINE DEPARTMENT OF DINAJPUR MEDICAL COLLEGE, DINAJPUR
}

\author{
Kazi Golam Moakhlesur Rahman ${ }^{1}$, Md. Mizanur Rahman ${ }^{2}$, Md. Rezaul Haque ${ }^{3}$
}

\begin{abstract}
Road Traffic Accident (RTA) is the most prevalent form of common offense in our country, while it is rare in other countries of the world. With the increasing use of the vehicles, injuries due to them are so common now-a-days that it is necessary for a medical man to be able to assess the injuries, the mechanisms by which they are caused, the cause of death \& if intoxication by alcohol or drugs played any part. The injuries often assume a definite and distinguishing pattern in the case of a pedestrian and a driver or a passenger, depening on the type of impact. A retrospective study was conducted on RTA death, in the department of Forensic Medicine in Dinajpur Medical College. About 200 cases were examined from June 2004 to June 2006, for two years. All the cases were referred from 13 different police stations of Dinajpur District. Among them the highest number cases were brought by Kotwali PS $\&$ the lowest from Hakimpur PS. 70\% victims were male victims. The highest frequency of offenses were found in lowest socio economic groups. The age group of them were from 32 to 45 years.
\end{abstract}

Keywords : Accidental death due to RTA, Reporting.

\section{Introduction}

Every form of transport is associated with risk and as the speed of transport increases as mechanization is involved, the risk of an accident is increased and the effects of an accident are magnified ${ }^{1}$. RTA is the most common form of accidental death in our country. The causes of accidents are not only related with the accused but also associated with multiple factors related with the victims. An appropriately performed autopsy can reveal the various factors contributing to the accident ${ }^{2}$.

1. Environmental factors : eg. Defect in the road, presence of ice over road, poor visibility due to fog, obscure traffic signals and air pollution with carbon monoxide.

2. The mechanical factors : eg. Defective brakes, presence or absence of seat belt, air bag collapsible steering.

3. Antecedent factors in the victim such as epilepsy, cardiac syncope, in take of alcohol or any other drug that may lead to accident. Now a days different papers published the incidents of accidental deaths with due importants though many cases are not reported due to social stigma, fear etc. In fact, the accidental cases are much higher than the cases recorded by authority.

\section{Methods}

The study was carried out from June 2004 to June 2006. During this years call the cases were referred from different 13 police stations of Dinajpur District to the Forensic medicine department of Dinajpur Medical College. The data was collected from the victims or from relative of the Victims.

\section{Result}

About 200 cases were brought by 13 police stations and 1 railway station for medicolegal examination to department of Forensic Medicine, Dinajpur Medical College. The highest cases of the victims were noted in table-1. The age group (30-35) years noted in table-2. According to special opinion, no definite opinion of accident was given. According to police station, the highest frequency about $20 \%$ was from Kotwali Police Station \& lowest 2.5\% was from Hakimpur Police Station.

Table-I

\begin{tabular}{lllll}
\hline Class - & No of cases & Total \\
\hline Upper & 30 (in 2004) & 35 (in 2005) & 40 (in 2006) & 105 \\
Middle & 35 (in 2004) & 30 (in 2005) & 14 (in 2006) & 79 \\
Lower & 65 (in 2004) & 70 (in 2005) & 60 (in 2006) & 195 \\
\hline
\end{tabular}

The Table-I shows the no. of cases on the basis of socio economic class.

1. Associated Professor, Forensic Medicine Department, Dhaka Medical College.

2. Associated Professor, Forensic Medicine Department, Enam Medical College, Savar, Dhaka.

3. Professor, Forensic Medicine Department, Enam Medical College, Savar, Dhaka. 
Table-II

\begin{tabular}{lccc}
\hline Age group (in years ) - & No of cases in each year & \\
\hline 0-20 years & 1 (in year 2004) & 5 (in year 2005) & 4 (in year 2006) \\
$20-30$ years & 15 (in year 2004) & 10 (in year 2005) & 14 (in year 2006) \\
$30-40$ years & 60 (in year 2004) & 70 (in year 2005) & 70 (in year 2006) \\
$40-50$ years & 30 (in year 2004) & 35 (in year 2005) & 45 (in year 2006) \\
\hline
\end{tabular}

The Table-II shows the no. of cases on basis of age group.

\section{Discussion}

A road traffic injury is a fatal or non fatal injury incurred as a result of a collision on a public road involving at least one moving vehicle, Children, pedestrian, cyclist and the elderly are the most vulnerable of road users ${ }^{3}$. Amongst of all traffic accidents, road traffic accidents (RTA) claims the largest toil of human life and tend to be the most serious problem. Almost 12 million people die all over the world due to RTA ${ }^{4}$. RTA cases are increasing day by day as no. of population increases accordingly the vehicles are increasing. According to police research and development, the no. of RTA cases has been increasing continually in Bangladesh than the previous years. If we look at the daily newspapers, there are new cases of RTA. One study shows that RTA cases increases more with middle age group as well as those who are socio economically lagging behind.

In order of frequency, the injuries can be described as 1. Vehicular injuries by mechanical vehicle, 2. Railway injuries and 3. Aircraft injuries ${ }^{5}$.

Injuries and fatalities occur in all forms of transportation but numerically road traffic accidents account for the great majority world wide. In develop countries, they are the most common causes of death below the age of 50 years and in young man this trend is more marked. RTA comprise of mostly injuries to the limbs, face externally, while more commonly head sustained internal injury ${ }^{6}$.

\section{Conclusion}

Amongst of all traffic accident RTA claims the largest toil of human life and tend to be the most serious problem world wide. Children, pedestrians, cyclist and the elderly are among the most vulnerable of road users. We must care for those accidents and try to take necessary steps to overcome those accidents.

\section{References :}

1. Simpsom's Forensic Medicine, $12^{\text {th }}$ Edition, Transportation Injury, Page 87.

2. Parikh's Text book of Medical Jurisprudence, Forensic Medicine and Toxicology, $6^{\text {th }}$ Edition, Transportation Injury, Page 4.139.

3. World Health Organization, Road Traffic Injuries (Internet).

4. Forensic Pathology, by Barnard Knight, $2^{\text {nd }}$ Edition, Transportation Injury, Page 275.

5. Text Book of Forensic Medicine and Toxicology, by Nagesh Kumar G Rao, $2^{\text {nd }}$ Edition, Transportation Injury, Page 259.

6. Text Book of Forensic Medicine and Toxicology, by Nagesh Kumar G Rao, $2^{\text {nd }}$ Edition, Transportation Injury, Page 259. 